U.S. Department of Commerce, Bureau of Standards

RESEARCH PAPER RP629

Part of Bureau of Standards Journal of Research, Vol. 11, December 1933

\title{
RADIO OBSERVATIONS OF THE BUREAU OF STANDARDS DURING THE SOLAR ECLIPSE OF AUGUST 31, 1932
}

\author{
By S. S. Kirby, L. V. Berkner, T. R. Gilliland, and K. A. Norton
}

\section{ABSTRACT}

Radio observations of the heights of the several layers of the ionosphere were made at Washington, D.C., and Sydney, Nova Scotia, by the pulse method during the afternoon of the solar eclipse of August 31, 1932, and during the afternoons of several days preceding and following. At Washington three separate groups of determinations were made: (1) measurements of the maximum ionization of the E-layer during the afternoon; (2) continual series of measurements of virtual height during the afternoon at $4,200 \mathrm{kc} / \mathrm{s}$ which was ordinarily just above the $F_{1}$ critical frequency for the ordinary ray; (3) measurements of the critical frequency of the $\mathrm{F}_{2}$-layer during the afternoon. At Sydney, determinations similar to (1) were made and continuous records of virtual height were obtained at $2,400 \mathrm{kc} / \mathrm{s}$ and $3,000 \mathrm{kc} / \mathrm{s}$. Separate equipment was used for each of these groups of determinations so that measurements could be made rapidly and continuously.

It was found that the ionization of the E-layer decreased to about 30 percent of its normal value at the time of the eclipse maximum, the variation taking place approximately in phase with the eclipse. The ionization of the $F_{1}$ layer likewise decreased in almost exactly the same manner, reaching a value of about 40 percent of its normal ionization at about the eclipse maximum. When analyzed by the method presented in this paper, observations of other investigators are found to agree well with these results. No unusual change was evident in the $\mathrm{F}_{2}$ critical frequency during the eclipse. No evidence of a corpuscular eclipse was found at either Washington or Sydney.

\section{CONTENTS}

I. Introduction

II. Experimental results 831

III. Observations of the E-layer

IV. Investigations of the $\mathrm{F}_{1}$-layer

V. Observations of the $\mathrm{F}_{2}$-layer

VI. Acknowledgments ...... 845

\section{INTRODUCTION}

Various investigators have suggested that ultraviolet radiation from the sun is responsible for part, if not all, of the ionization in the upper atmosphere. However, the fact that more layers than one are present indicates the possibility that the source of the ionization of one layer may be different from that of the others. Some investigators believe that the ionization in the upper region is so great that most of the ultraviolet radiation is absorbed and that some other agency may be required to explain the ionization of the lower layers. It has been suggested by Professor Chapman ${ }^{12}$ in England that the lower region of ionization is caused by neutral corpuscles shot out from

1 Chapman, Monthly Notices of R.A.S., March 1932.

2 Appleton \& Chapman, Nature, May 21, 1932. 
the sun. It has been shown that such corpuscles are likely to be emitted by radiation-pressure acting upon atoms and that a velocity of about $1,600 \mathrm{~km} / \mathrm{s}$ away from the sun may be attained. At present there is no observational proof that such particles are present, but if they exist and are responsible for any appreciable part of the ionization in the upper atmosphere, an eclipse of the sun should offer an opportunity to show just how important this agent is.

If ultraviolet radiation and particle bombardment were both important, we might expect the effect of one to be cut off before the other because of their different velocities, and changes during the eclipse to be much more abrupt and clear cut than the changes noted from day to night. Calculations indicate that the particle eclipse should occur approximately 2 hours before the light eclipse. According to Chapman's calculations on the basis of a particle velocity of $1,600 \mathrm{~km} / \mathrm{s}$, the corpuscular eclipse track would lie to the east of the optical-eclipse track, and should be observed in northeastern North America.

In order to study this effect, observations were made in Washington, D.C., and Sydney, Nova Scotia, the latter lying within the area of the suggested corpuscular eclipse. As Washington was to the west and Sydney to the east of the optical eclipse, and both points were subject to approximately 90 percent optical totality, the magnitude of changes at the two places due solely to ionizing sources travelling from the sun at the velocity of light should be of the same order.

An expedition comprising Messrs. Gilliland, Norton, and Carnes proceeded to Sydney. The equipment was taken in two laboratory trucks. Observations were made at Washington by Messrs. Kirby and Berkner.

In order to study possible optical and corpuscular effects, it was decided to make a series of determinations of the maximum ionizations of the various layers when facilities permitted and lacking these, to make continuous records of virtual heights at frequencies so selected as to give as much information as possible regarding the changes of such maximum ionizations. The critical frequency of a layer has been defined as the lowest frequency which penetrates the layer. This frequency is a measure of the maximum ionization. These measurements, therefore, involved the determination of a series of critical frequencies, each determination requiring a series of from 5 to 10 measurements. This procedure has been completely described elsewhere. ${ }^{3}$

The general method used was that of Breit and Tuve ${ }^{4}$ as adapted and described ${ }^{567}$ in previous Bureau of Standards publications. For the somewhat specialized apparatus of the expedition, two types of oscillograph were employed for measurements. A cathode-ray tube was used for visual work and manual measurements while a string oscillograph was used for continuous photographic recording.

A new method was employed for measuring the pulse-retardation time on the cathode-ray oscillograph. The sweep-circuit voltage was

3 Kirby, Berkner, and Stuart, Studies of the ionosphere and their application to radio transmission, B.S.Jour. Research, vol. 12, January 1934 .

1 Breit and Tuve, Terr. Mag., vol. 30, p. 15, 1925. Nature, vol. 116, p. 357, Sept. 5, 1925. Phys. Rev., vol. 28, p. 554, September 1926 .

$\checkmark$ Gilliland, B.S.Jour. Research, vol. 6, November 1930. Proc.I.R.E., vol. 19, p. 114, January 1931.

6 Gilliland, Kenrick, and Norton, B.S.Jour. Research, vol. 7, p. 1083, December 1931. Proc.I.R.E., vol. 20, p. 286, February 1932 .

7 See footnote 3. 
taken from the 60-cycle alternating-voltage supply and the pulses were shifted across the screen a known interval of time by means of a phase-shifting bridge similar to that described by Turner and McNamara. ${ }^{8}$ The rheostats in the phase-shifting bridge which shifts the phase of the sweep-circuit voltage, were calibrated directly in virtual height, the relation between resistance and virtual height being almost linear. Pulse-retardation time was measured as follows. The ground pulse was centered on the screen by means of an auxiliary bridge, preceding the calibrated bridge. Then the rheostats in the calibrated bridge were adjusted until the pulses corresponding to the various layers were centered on the screen. The corresponding heights were read from the rheostat dial.

In addition to the cathode-ray oscillograph at Sydney, the automatic recording equipment described by Gilliland and Kenrick ${ }^{9}$ was used. At Washington a visual recorder with galvanometer oscillograph was used for measuring E-layer critical frequency and also for the measurements at $4,200 \mathrm{kc} / \mathrm{s}$. A manually-operated photographic recorder was used to measure the $\mathrm{F}_{2}$ critical frequency at Washington.

At Sydney the manual measuring equipment was designed to make a series of critical-frequency determinations of the E-layer, while the continuous recorder was used to make virtual height records at two frequencies which would show changes in the E-layer if its critical frequency decreased. The rest of the apparatus consisted of a portable transmitter and receiver operating with each measuring equipment.

At Washington, three transmitters were located at the Bureau's field station at Beltsville, Md., and two receivers were set up at Kensington, $\mathrm{Md}$. One receiver was alternately tuned to a fixed frequency of $4,200 \mathrm{kc} / \mathrm{s}$ and to a series of frequencies near the $\mathrm{E}$ critical frequency, while the second was used for $\mathrm{F}_{2}$-layer critical frequency determinations. The measuring equipment has been described elsewhere. ${ }^{10} 1112$

\section{EXPERIMENTAL RESULTS}

In order to avoid ambiguity in reference to "critical" frequencies we will discuss them from the point of view of experimental observations. ${ }^{13}$ As the frequency is increased through a critical value for the $\mathrm{E}$ - or $\mathrm{F}_{1}$-layer, the ray penetrates the lower layer and is returned from the next higher layer. As the rise takes place, the signals are usually subject to long retardation and high absorption, so that high and rapidly changing virtual heights and small amplitudes are observed through a small range of frequency. The frequency corresponding to the greatest retardation (or sometimes complete absorption) at this virtual height change is interpreted as the critical frequency. The lower limit is the highest frequency at which reflections from the lower layer only are positively returned. The upper limit is the lowest frequency at which reflections from the upper layer are positively returned. These reflections are very much larger than those from the low layer which have a very small amplitude and usually occur above the critical frequency. The critical frequency for the $\mathrm{F}_{2}$-layer

\footnotetext{
8 Turner and McNamara, Proc.I.R.E., vol. 18, p. 1743, 1930.

${ }^{\circ}$ Gilliland and Kenrick, B.S.Jour. Research, vol. 7, p. 783, November 1931. Proc.I.R.E., vol. 20, p.540, March 1932.

10 See footnote 3, p. 830

11 See footnote 5, p. 830.

12 See footnote 6, p. 830

13 See footnote 3, p. 830 .
} 
is determined in a somewhat different manner. The greatly retarded signals at this critical frequency are often followed by scattered reflections of great virtual height and very small magnitude which have been shown to have no definite relation to the larger $\mathrm{F}_{2}$-layer reflec-

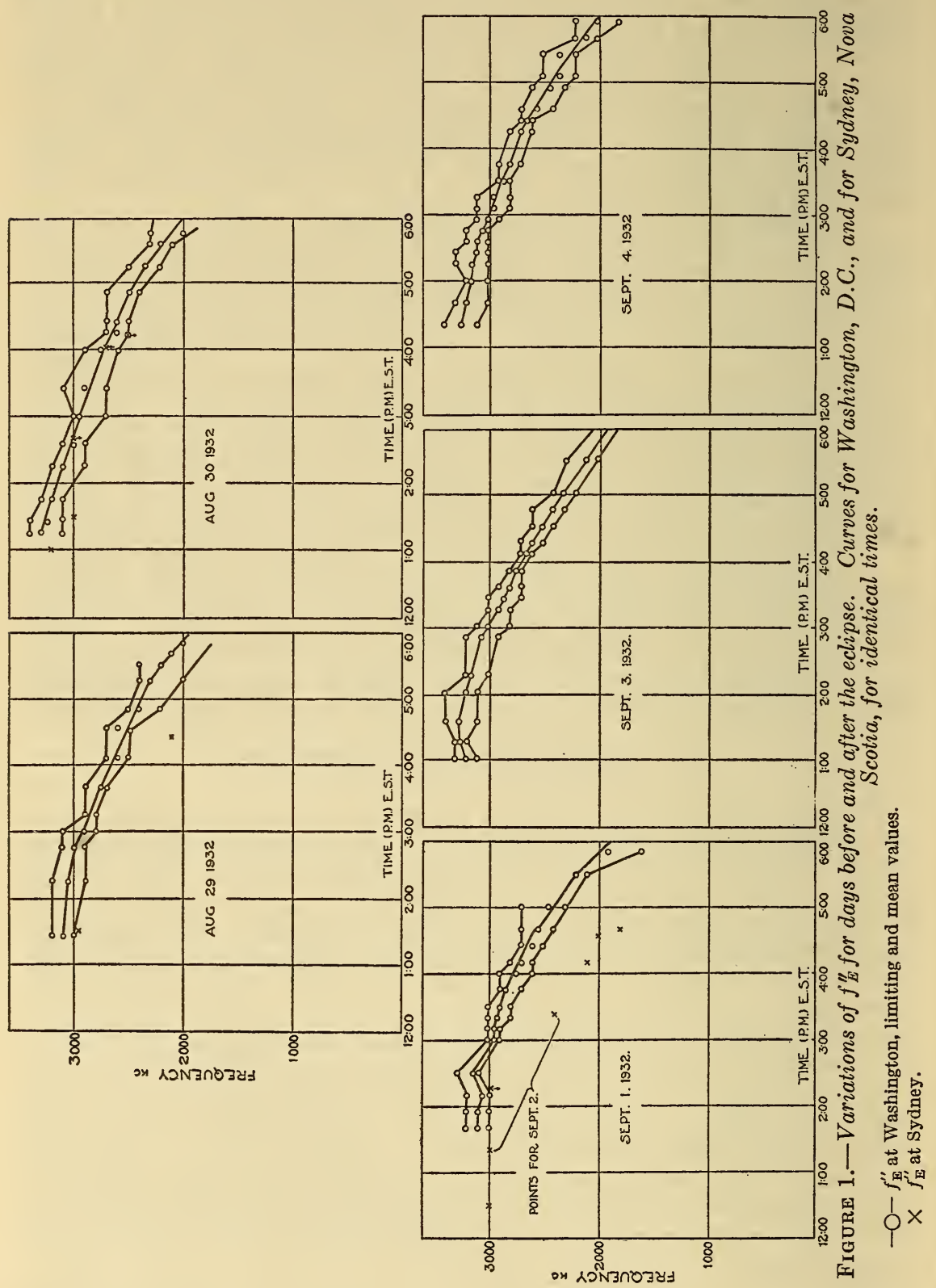


tions. The critical frequency for the $\mathrm{F}_{2}$-layer is taken as the frequency at which the slope of the frequency-height curve is a maximum, and above which the reflections are not of appreciable magnitude. The lower limit is considered as the beginning of the abrupt rise in the frequency-height curve, and the upper limit is indicated by the positive disappearance of any $\mathrm{F}_{2}$-layer reflections.

The disappearance of reflections alone is not believed to be always an exact indication of this critical frequency because the high absorption often extending to frequencies well below the critical frequency as defined, would make the results depend somewhat upon the sensitivity of the receiver. The appearance of "scattered reflections" often through an extended range above the critical frequency might also have an influence.

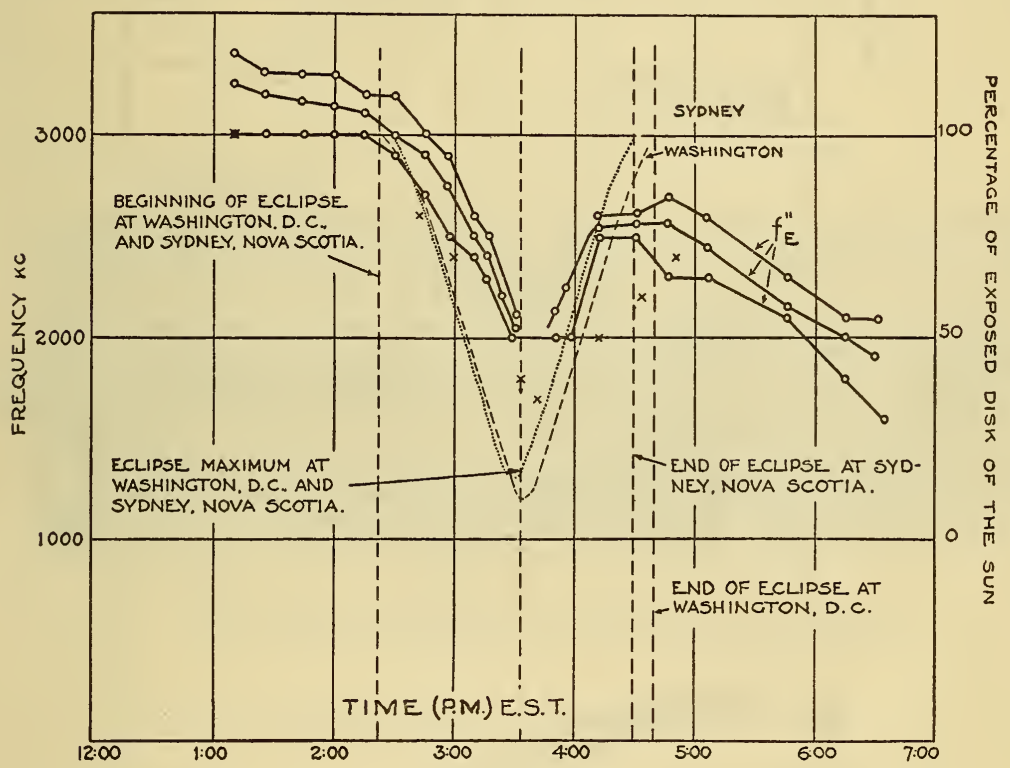

FIGURE 2.-Variations of $f_{E}^{\prime \prime}$ during the time of the eclipse together with the percentage of the exposed area of the sun's disk at Washington, D.C., and Sydney, Nova Scotia.

- $-f_{E}^{\prime \prime}$ at Washington, limiting and mean values.

$\times \quad \mathrm{f}_{\mathrm{E}}^{\prime \prime}$ at Sydney.

- - - Percentage of exposed disk of the sun at Washington.

..... Percentage of exposed disk of the sun at Sydney.

In order to be sure of complete control, observations were made between noon and 6 p.m. on several days before and after the eclipse, as well as on the day of the eclipse. The continuity of these experiments was interrupted only by adjustments of the apparatus and very severe atmospheric disturbances.

\section{OBSERVATIONS OF THE E-LAYER}

The daily variations of the E-layer critical frequency $\left(f_{E}^{\prime \prime}\right)$ are shown in figure 1 for days preceding and following the eclipse. Figure 2 shows the variation of $f_{\mathrm{E}}^{\prime \prime}$ on the day of the eclipse, together 
with the percentage of the exposed disk of the sun at Washington and Sydney. The solid line graphs show the values at Washington, while the individual crosses show the values at Sydney for identical times.

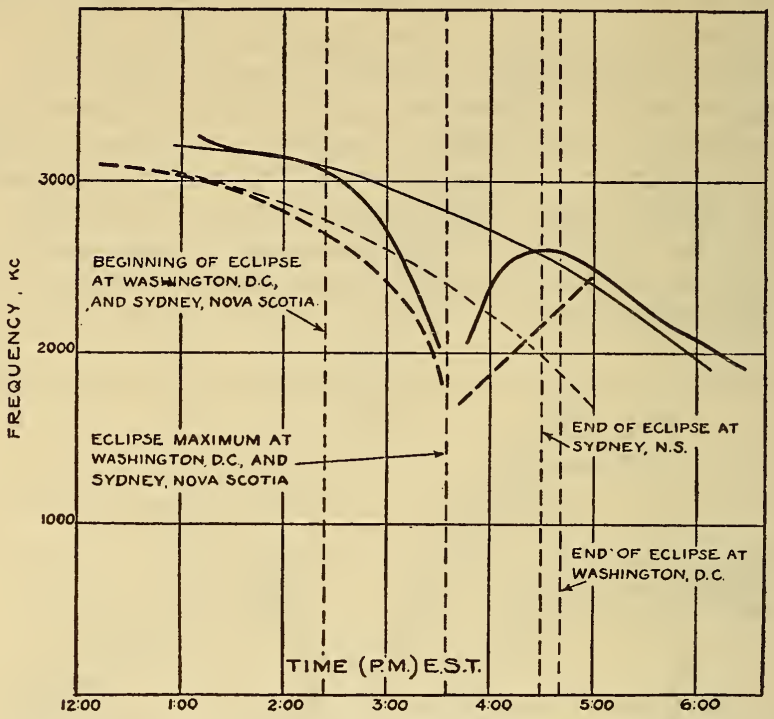

Figure 3.-Comparison of graphs of $f_{E}^{\prime \prime}$ at Washington and Sydney for the day of the eclipse and the mean graphs of 6 days preceding and following the eclipse.

$f_{\mathrm{E}}^{\prime \prime}$ at Washington on day of eclipse.

$-----f_{\mathbf{E}}^{\prime \prime}$ at Sydney on day of eclipse.

$f_{\mathrm{E}}^{\prime \prime}$ at Washington (average of days before and after the eclipse).

$----f_{E}^{\prime \prime}$ at Sydney (average of days before and after the eclipse).

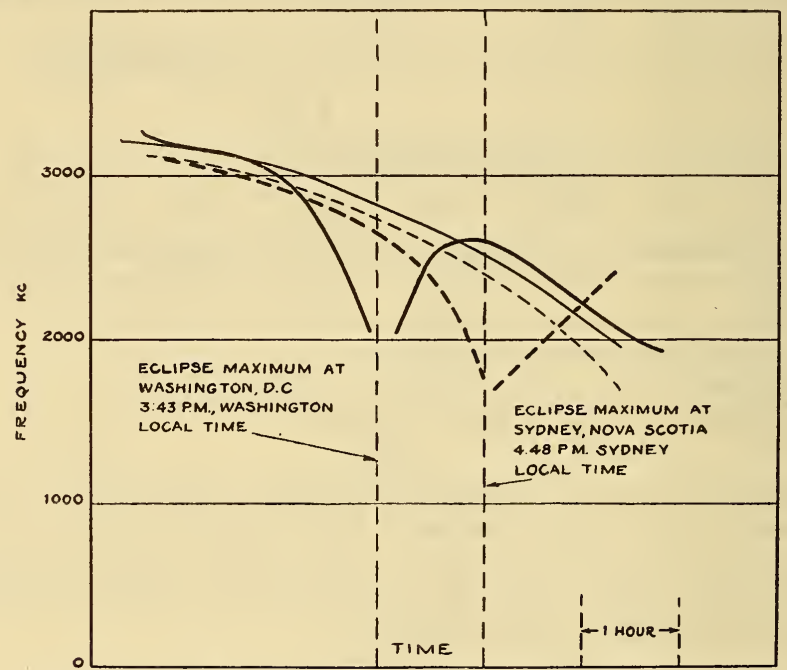

FIgURE 4.-Same as figure 3 except that the Sydney time is displaced to correct for the difference in longitude of the $\mathbb{2}$ stations.

The break in the dip of the $f_{\mathrm{E}}^{\prime \prime}$-graph taken at Washington occurred because the rapid change of $f_{\mathrm{E}}^{\prime \prime}$ during this period made accurate determinations impossible. The data show that it is probable 
B.S. Journal of Research, RP629

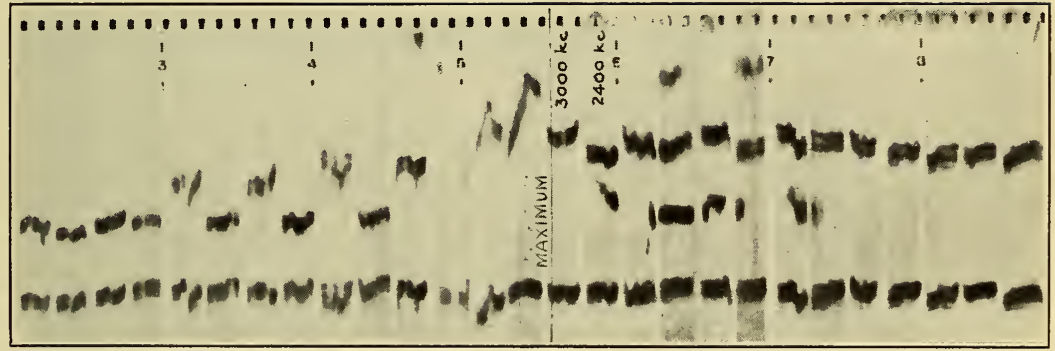

FIGURE 5.-Record showing virtual height variations of 2,400 and 3,000 kc/s during the eclipse at Sydney, Nova Scotia, August 31, 1932. 
that $f_{\mathrm{E}}^{\prime \prime}$ did not fall below $1,600 \mathrm{kc} / \mathrm{s}$ at Washington. Figure 3 shows the comparison of $f_{\mathrm{E}}^{\prime \prime}$ for the day of the eclipse and the mean of
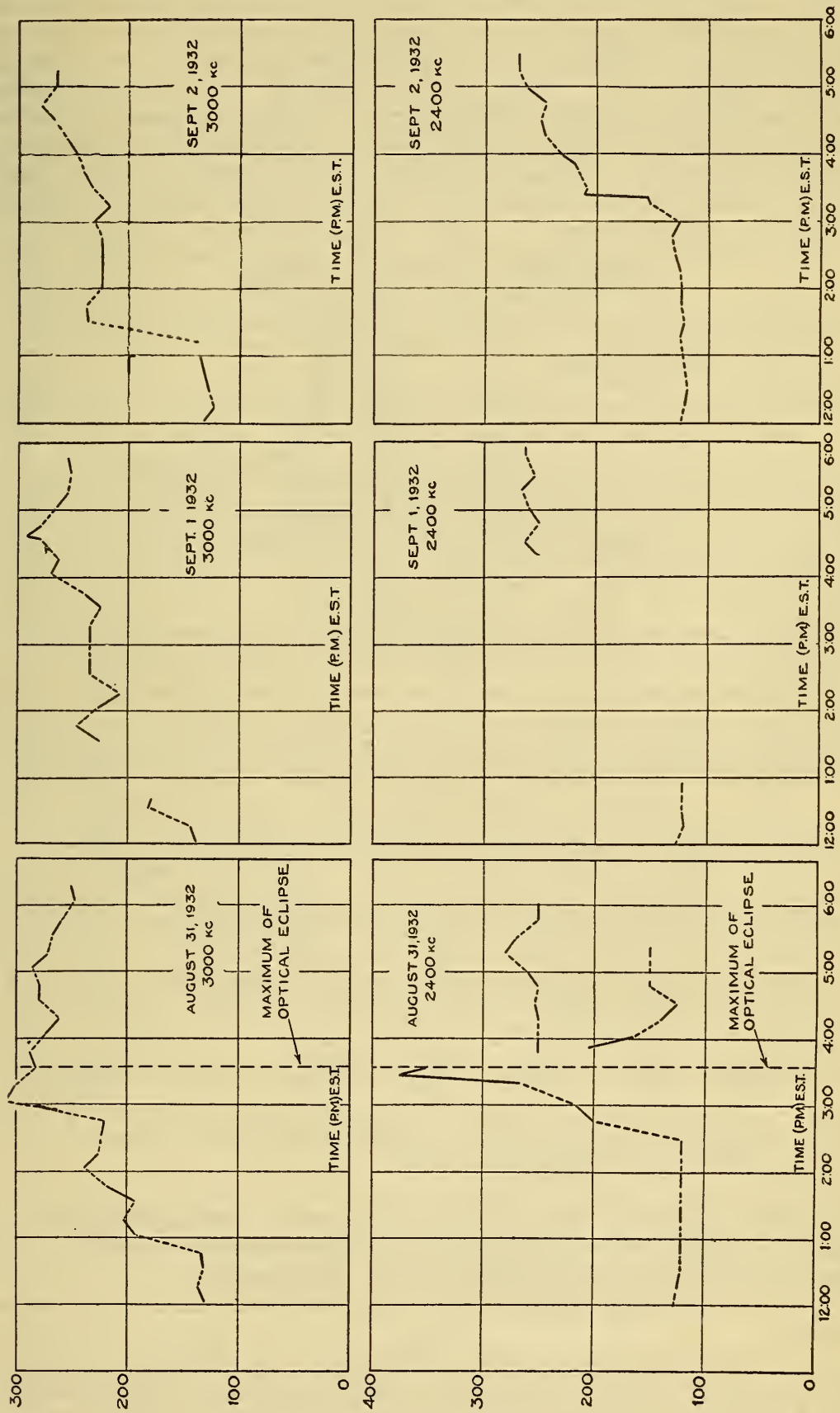

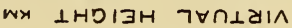

FiguRe 6.-Virtual heights of 2,400 and $3,000 \mathrm{kc} / \mathrm{s}$ plotted for the day of the eclipse and succeeding days at Sydney, Nova Scotia. 
the curves of figure 1 of the 6 days preceding and following the eclipse. Figure 4 shows the same graphs as figure 3 with those for Sydney displaced to correct for difference in longitude between Washington and Sydney. As might be expected, because of approximately $7.3^{\circ}$ difference in the declination of the sun due to latitude difference, the values of $f_{\mathrm{E}}^{\prime \prime}$ at Sydney are somewhat lower than corresponding values at Washington. Figure 5 shows the record of changes in virtual height at $2,400 \mathrm{kc} / \mathrm{s}$ and $3,000 \mathrm{kc} / \mathrm{s}$, respectively, for the day of the eclipse at Sydney, while figure 6 shows these changes plotted for the same period and compared with the 2 succes-
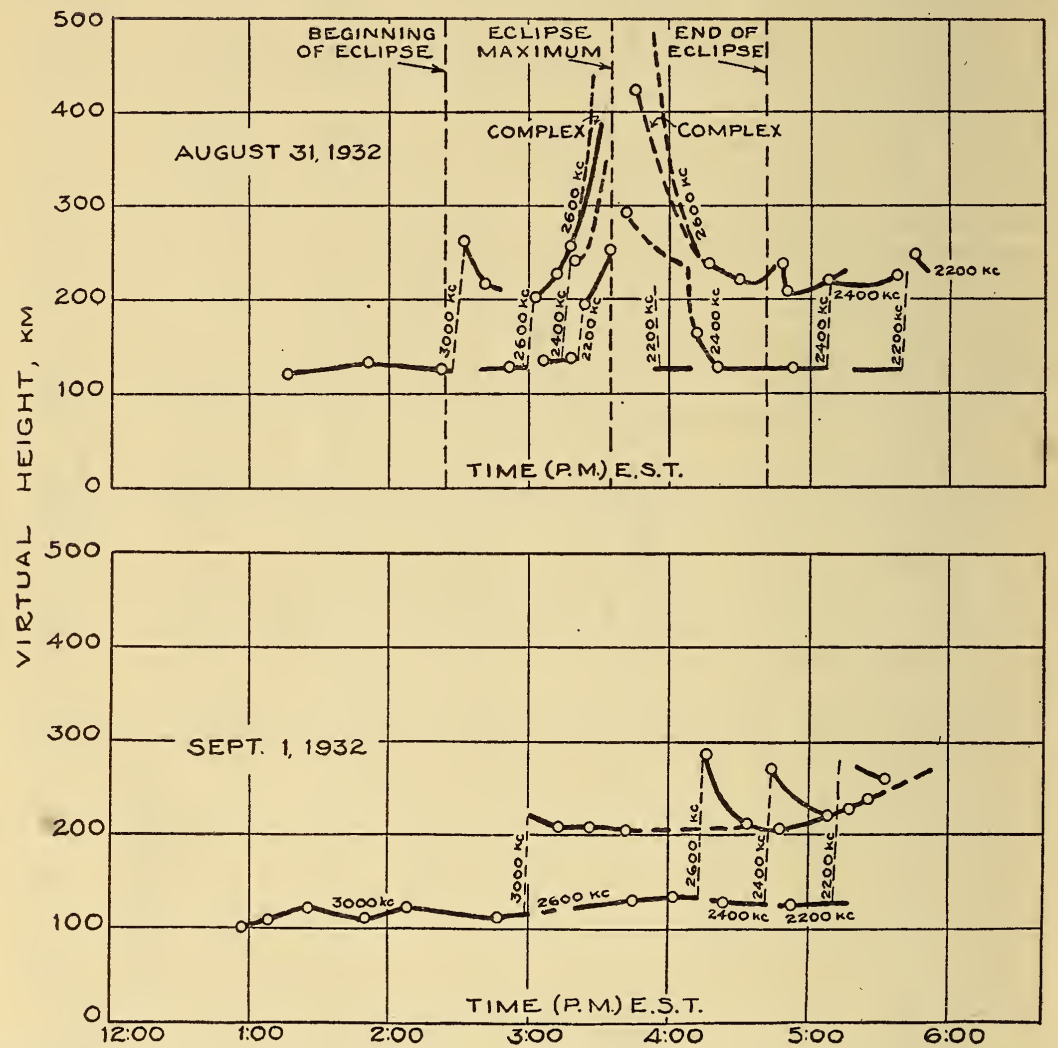

FIGURE 7.-Virtual height of a number of frequencies through which the $E$ critical frequency decreased during the eclipse period for the day of the eclipse and the day following the eclipse at Washington, D.C.

sive days. Figure 7 shows the variations in virtual heights for a number of frequencies through which $f_{\mathrm{E}}^{\prime \prime}$ decreased for the day of the eclipse and also for a succeeding day at Washington.

An examination of these curves brings out a number of points of interest:

(1) A marked decrease of the ionization of the E-layer during the optical eclipse, reaching a minimum almost exactly at (not more than 4 or 5 minutes after) the maximum of the optical eclipse at both Sydney and Washington. 
(2) No measurable deviation from the normal value of the ionization of the E-layer for the period just preceding the eclipse at either Sydney or Washington.

(3) A slightly higher than normal ionization of the E-layer at both Sydney and Washington for the period immediately following the eclipse.

(4) At Sydney a greater virtual height during the eclipse of about $280 \mathrm{~km}$ as compared with normal values of about $230 \mathrm{~km}$ for 3,000 $\mathrm{kc} / \mathrm{s}$, and nearly $400 \mathrm{~km}$ as compared with normal values of about $220 \mathrm{~km}$ for $2,400 \mathrm{kc} / \mathrm{s}$.

(5) Similar abnormally high values of virtual heights during the eclipse for frequencies just above $f_{\mathrm{E}}^{\prime \prime}$ at Washington.

These last two effects are discussed in section IV.

Since the reduction and following rise in $f_{\mathrm{E}}^{\prime \prime}$ at both stations coincided almost exactly with corresponding phases of the optical eclipse, we conclude that at least that part of the ionization of the E-layer affected by the eclipse is due to an ionizing force from the sun travelling at the velocity of light rather than to corpuscular effects.

It has been shown ${ }^{14}$ that the maximum ionization of the layer is proportional to $f_{\mathrm{E}}^{\prime \prime 2}$. Taking a value of $2,850 \mathrm{kc} / \mathrm{s}$ for $f_{\mathrm{E}}^{\prime \prime}$ at the time of the eclipse on a normal day, and $1,650 \mathrm{kc} / \mathrm{s}$ for $f_{\mathrm{E}}^{\prime \prime}$ for the minimum during the eclipse from figure 3 , we find that the ionization decreased to one third of its normal value during the eclipse. It can be said qualitatively from an examination of the results that the magnitude of the ionization from the source just described seems adequate to account for the greater part of the ionization of the E-layer in the daytime. Exact recombination rates have not yet been computed from the data. An analytical discussion is in preparation with comparisons with ordinary night results with the view of determining the relative importance of this ionizing force and others known to exist under certain circumstances, ${ }^{15} 161718$ particularly at night.

A report of somewhat similar observations made by Canadian experimenters ${ }^{19}$ during the eclipse period shows a very close correspondence with our results. It is noted that the slight increase above normal values of $f_{\mathrm{E}}^{\prime \prime}$ which they observe following the eclipse has been attributed to thunderstorm conditions which occurred at that time. Apparently identical increases already mentioned in connection with the results at Sydney and Washington were observed during fair weather at both places and it is believed that this increase must have been somewhat general and not the result of local meteorological conditions.

\section{INVESTIGATIONS OF THE $F_{1}$ LAYER}

It has been shown ${ }^{20}$ that the F-region is divided into two layers during the daytime. These have been termed the $\mathrm{F}_{1}$ - and $\mathrm{F}_{2}$-layers. The maximum ionization of the $\mathrm{F}_{1}$-layer is indicated by a critical frequency somewhat higher than $f_{\mathrm{E}}^{\prime \prime}$. At noon on the date of the eclipse, the critical frequency was about $4,200 \mathrm{kc} / \mathrm{s}$.

\footnotetext{
14 Pedersen. Propagation of Radio Waves, chapter XI.

1s See footnote 3 , page 830 .

16 Schafer and Goodall, Proc. I.R.E., vol. 20, p. 1131, July 1932 (also 1931).

17 Gilliland, B.S.Jour.Research, vol. 9, July 1933.

18 Ranzi, Nature, vol. 130, p. 368, Sept. 3, 1932.

10 Henderson, Canadian J.R., p. 1,1933 .

${ }_{20}$ See footnotes 3 and 17, p. 830; also see Gilliland, B.S. Jour. Research, vol. 11, p. 561, 1933. 18745-33-8
} 
Facilities did not permit a continuous determination of the critical frequency of the $F_{1}$-layer. Measurements were therefore made in Washington at a fixed frequency of $4,200 \mathrm{kc} / \mathrm{s}$.

Figure 8 shows the virtual heights for $4,200 \mathrm{kc} / \mathrm{s}$ on the days preceding and following the eclipse, and figure 9 shows the virtual heights
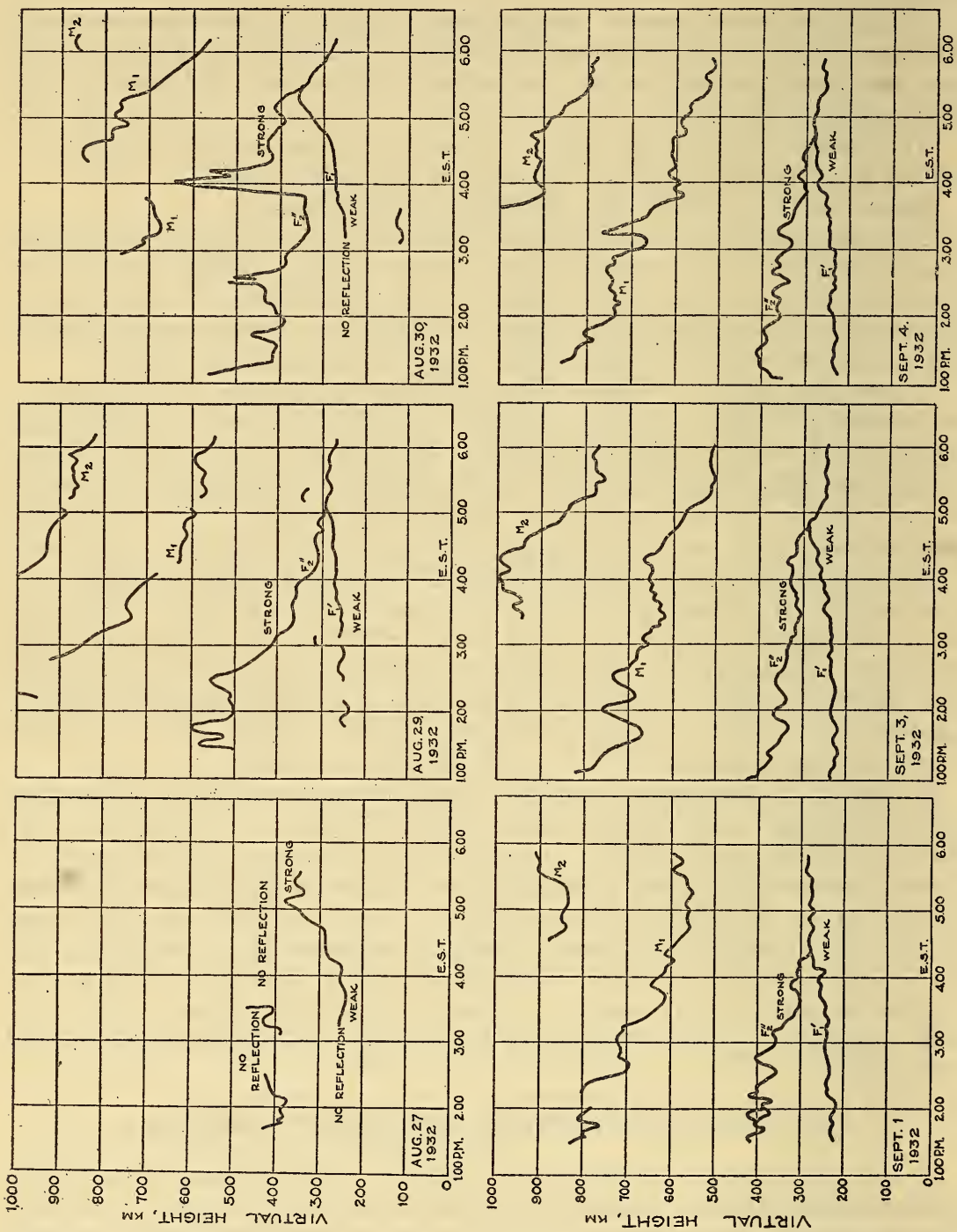

FIGURE 8.-Virtual heights for a frequency near the noon value of $f_{\mathrm{F} 1}^{\prime \prime}(4,200 \mathrm{kc} / \mathrm{s})$ for days preceding and following the eclipse.

for this frequency on the day of the eclipse. It has been shown ${ }^{21}$ that retardations at this critical frequency for the $\mathrm{F}_{1}$-layer are frequently subject to a considerable variation during terrestrial magnetic disturbances and therefore the results for August 27, 29, and 30 cannot be considered as representative of normal conditions. Figure

\footnotetext{
${ }^{21}$ See footnote 3, page 830 .
} 
10 , therefore, shows figure 9 superimposed on the envelope of the virtual heights for the undisturbed days of September 1,3 , and 4 . The variations in virtual height are seen to be quite complex, and the characteristic phenomena associated with the $\mathrm{F}_{1}$-layer must be taken into consideration in the interpretation of the results.

It has been suggested that the maximum ionization of this layer may be manifest by two critical frequencies because of magnetic double refraction. If we let $\mathrm{f}^{\prime \prime}{ }_{F 1}$ denote the ordinary critical frequency and $f_{F 1}^{\prime}$ the extraordinary critical frequency, then ${f^{\prime \prime 2}}_{F 1}=f_{F 1}^{\prime}$ $\left(\mathrm{f}_{\mathrm{F} 1}^{\prime}-\mathrm{f}_{\mathrm{h}}\right){ }^{22}{ }^{23}$ where $\mathrm{f}_{\mathrm{h}}=1,450 \mathrm{kc} / \mathrm{s}^{24}$ Effects have been observed which appear to confirm this result. ${ }^{25}$ At the first critical frequency, therefore, the reflection would consist of two components, reflected

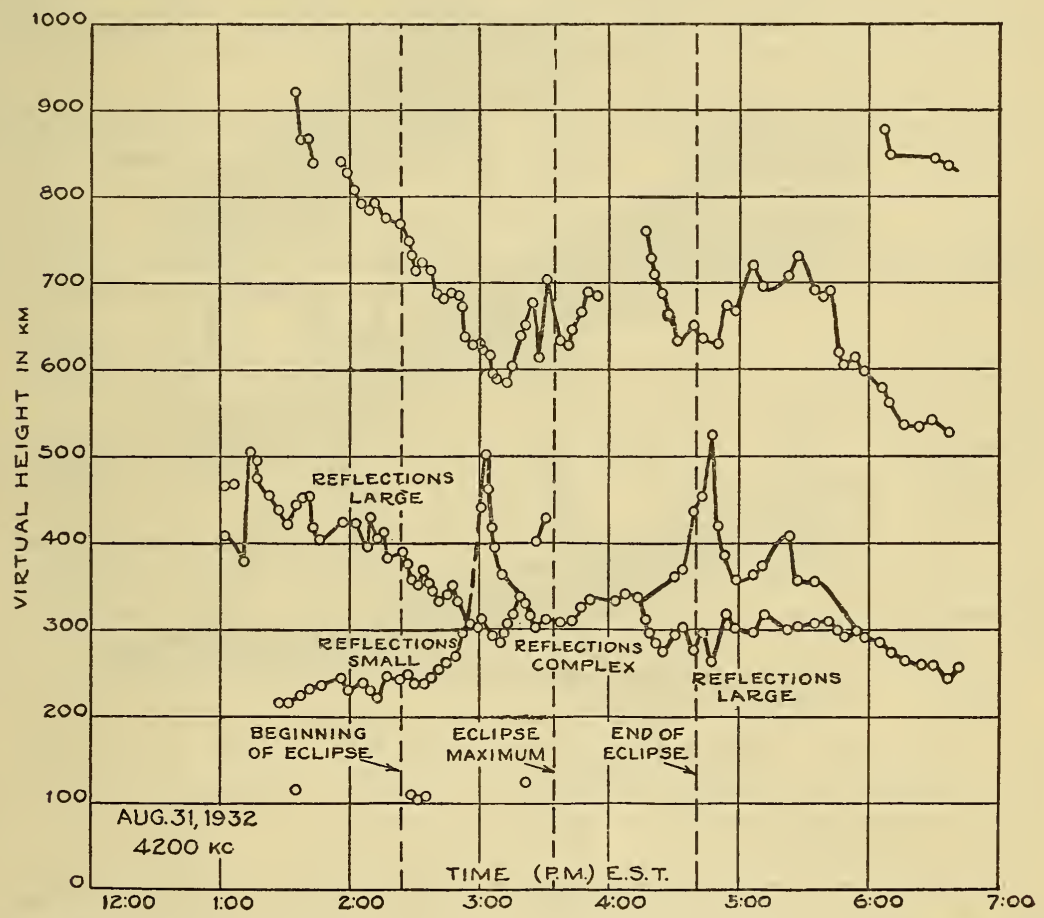

FIGURE 9.-Virtual heights for a frequency near the noon value of $\mathrm{f}^{\prime \prime}{ }_{\mathrm{F} 1}(4,200 \mathrm{kc} / \mathrm{s})$ for the day of the eclipse.

from different parts of the F-region. The component for which the lesser reduction in refractive index occurs has been termed the ordinary ray designated here as $F^{\prime \prime}{ }_{1}$, having a critical frequency of $f^{\prime \prime}{ }_{F 1}$. At a frequency just above $f^{\prime \prime}{ }_{F 1}$, this ray will be reflected from the $\mathrm{F}_{2}$-layer, but will be subject to a retardation in the $\mathrm{F}_{1}$-layer and is then termed $\mathrm{F}^{\prime \prime}{ }_{2}$. The component for which the greater reduction in refractive index occurs has been termed the extraordinary ray designated here as $\mathrm{F}^{\prime}{ }_{1}$ and having a critical frequency of $f^{\prime}{ }_{\mathrm{F} 1}$. It can be shown that the component for which the greater reduction in refractive

22 See footnote 3, p. 830 .

${ }^{23}$ Appleton \& Builder, Proc. Phys. Soc., vol. 45, part 2, no. 247, p. 208, March 1933

24 This frequency has been determined by assuming a value of 0.52 gauss for the total earth' magnetic field at a height of $180 \mathrm{~km}$ at Washington.

25 See footnotes 3 , p. $830 ; 20$, p. 837 , and 23 . 
index occurs $\left(\mathrm{F}^{\prime}{ }_{1}\right)$ will be subject to the greater absorption, at a given frequency. ${ }^{26}$

Referring to figure 8 , it is seen that on normal days two components are present. At noon at this frequency the amplitude of the upper reflection is about 1,000 times as large as the lower reflection. It is probable that these two components are due to the double refraction effects just discussed. It is seen that $4,200 \mathrm{kc} / \mathrm{s}$ will lie between $f^{\prime \prime}{ }_{F 1}$ and $f^{\prime}{ }_{F 1}$ during the course of the afternoon. In this case the upper reflection at noon is the ordinary ray reflected from the $\mathrm{F}_{2}$-layer, and suffering long retardation due to its proximity to $f^{\prime \prime}{ }_{F 1}$. The lower reflection is the extraordinary ray, $F_{1}^{\prime}$. It has been shown ${ }^{27}$

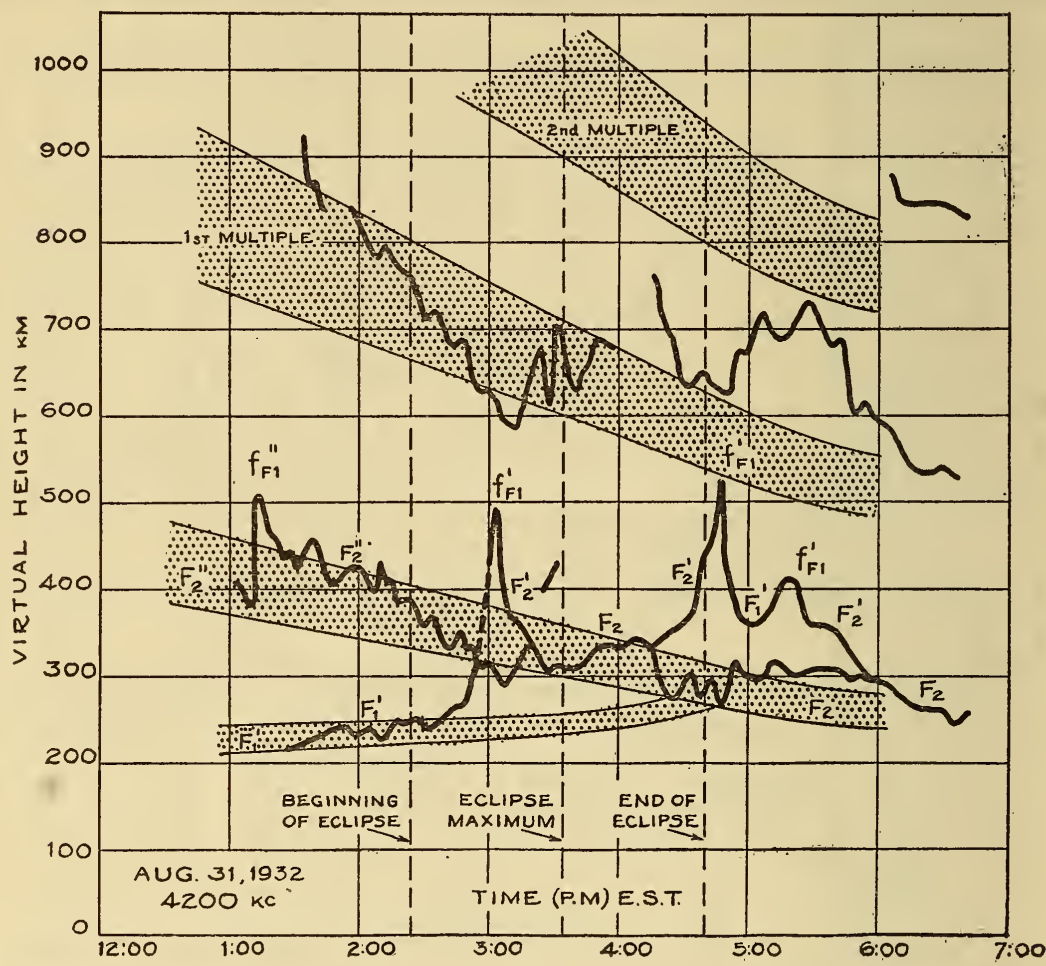

FIGURE 10.-Virtual heights for a frequency near the noon value $f^{\prime \prime}{ }_{F 1}(4,200 \mathrm{kc} / \mathrm{s})$ for the day of the eclipse superimposed on the envelope of the virtual heights for the undisturbed days following the eclipse.

that for magnetically undisturbed days the upper reflection will generally fall in height during the afternoon for two reasons: (1) The decrease in $f^{\prime \prime}{ }_{F 1}$, and (2) the decrease in long retardation at $f^{\prime \prime}{ }_{F 1}$. At the same time, the virtual height for the extraordinary ray is seen to rise because of the decrease of $f^{\prime}{ }_{F 1}$ toward the recorded frequency until the reflected ray joins the $\mathrm{F}_{2}$ reflection. It is known that the long retardations at $f^{\prime \prime}{ }_{F 1}$ and $f^{\prime}{ }_{F 1}$ are not so great as the afternoon progresses, disappearing in the evening. This effect probably accounts for the fact that on the normal days long retardations

\footnotetext{
${ }^{26}$ See footnote 23, p. 839 .

27 Seeffootnote 3, p. 830 .
} 
accompaning the critical frequency of the second component $\left(\mathbf{F}^{\prime}{ }_{1}\right)$ are not observed on $4,200 \mathrm{kc} / \mathrm{s}$ as recombination progresses.

During the day of the eclipse somewhat different effects were observed as illustrated in figure 9 . It seems that the rapid decrease in virtual height of the upper reflection after the commencement of the eclipse must have been due to a rapid decrease in $f^{\prime \prime}{ }_{F 1}$. At the same time, since there was a corresponding decrease of $f_{F 1}^{\prime}$, the lower reflection rose rapidly in virtual height and appeared to cross the other reflection, reaching a critical value at 3:03 p.m. It appears that $4,200 \mathrm{kc} / \mathrm{s}$ becomes the critical frequency at this time for the "extraordinary" ( $\left.\mathrm{F}_{1}^{\prime}\right)$ ray. The virtual height for this ray then fell, joining the other which was then returned from somewhat high $\mathrm{F}_{2}$ virtual heights. At 4:17 p.m., the reflections again split and it appears that ${f^{\prime}}_{\text {F1 }}$ again passed through $4,200 \mathrm{kc} / \mathrm{s}$ at $4: 47 \mathrm{p} . \mathrm{m}$. as it rose as reionization took place. $f_{F 1}^{\prime}$ finally again fell below 4,200 $\mathrm{kc} / \mathrm{s}$ at $5: 13 \mathrm{p} . \mathrm{m}$. As might be expected, this last critical effect is less distinct than the earlier effects. This was followed by the normal return of reflections from $\mathrm{F}_{2}$-layer heights. This analysis brings out certain points of interest. Ordinarily, it is not possible to use a single frequency for determining the decrease of $f^{\prime \prime}{ }_{F 1}$ and $f_{F 1}^{\prime}$ resulting from recombination, because these effects disappear toward evening. These observations therefore add confirming evidence of the existence of magnetic double refraction.

It has been shown that the difference in frequency between $f_{\mathrm{F} 1}^{\prime \prime}$ and $f_{\mathrm{F} 1}^{\prime}$, is a definite function of $f_{\mathrm{F} 1}^{\prime \prime}$ and the total magnetic field of the earth. When the value of $f_{\mathrm{F} 1}^{\prime}$ is $4,200 \mathrm{kc} / \mathrm{s}, f_{\mathrm{F} 1}^{\prime \prime}$ is $3,405 \mathrm{kc} / \mathrm{s}$. Knowing the times at which the observed frequencies passed through $f_{\mathrm{F} 1}^{\prime \prime}$ and $f_{\mathrm{F} 1}^{\prime}$ and using this separation, it is possible to obtain a series of points for $f_{\mathrm{F} 1}^{\prime \prime}$, as plotted in figure 11 .

It appears from the discussion of the data obtained during the investigations of the E-layer that the abnormal virtual heights occurring at about $2,500 \mathrm{kc} / \mathrm{s}$ at the eclipse maximum were probably due to the decrease of $\mathrm{f}_{\mathrm{F} 1}^{\prime \prime}$ to this frequency. This was shown in figure 7 . The normal diurnal variation is also plotted.

From these data it is possible to estimate the magnitude of the decrease of ionization from the normal during the eclipse. The ratio of $\left(f_{\mathrm{F} 1}^{\prime \prime}\right)^{2}$ at the eclipse maximum to the normal value is 0.40 . Since this change in ionization took place practically in phase with the optical eclipse, we can therefore conclude that the portion of ionization represented by this drop in critical frequency was due, in this layer also, to an ionizing agency traveling from the sun at the velocity of light.

At Sydney, $f_{\mathrm{F} 1}^{\prime \prime}$ was determined directly from the automatic records as shown in figures 5 and 6 . These points seem reasonably consistent with the Washington data when it is considered that the eclipse occurred a few minutes earlier at Sydney.

The published reports of a number of observers ${ }^{28} 2930$ have been examined and it seems that the variation of virtual heights at frequencies through which $f_{\mathrm{F} 1}^{\prime \prime}$ and $f_{\mathrm{F} 1}^{\prime}$ decrease can be interpreted in the same manner. From these data, a number of additional points are available, and are shown in figure 11. The variation of the points from

${ }_{28}$ Kenrick and Pickard, Proc.I.R.E., vol. 21, p. 546, April 1933.

29 Mimno \& Wang, Proc.I.R.E., vol. 21, p. 529, April 1933.

30 Henderson, Can. Jour. Research, vol. 8, p. 1, January 1933. 
the dotted curve is to be expected from the differences in latitude and percent totality. It is striking that these points of various observers follow so closely the variation of ionization shown by this interpretation. The interpretation of these effects in terms of a corpuscular eclipse as suggested by Mimno and Wang does not seem to be necessary.

It is of particular interest that the retardations at $f_{\mathrm{F} 1}^{\prime}$ remained long until very late in the afternoon. It has been mentioned that the usual disappearance of these effects from the $F_{1}$-layer during the afternoon might be due to an actual shifting of the layer. It is evident from the data obtained after the eclipse that the usual cause

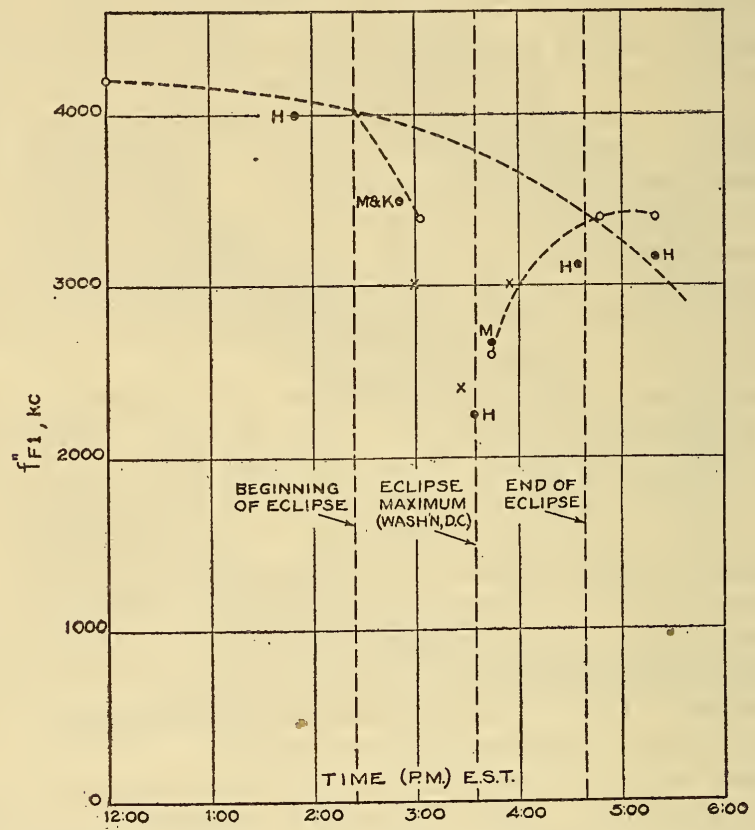

FIGURE 11.-Variation of $f_{\mathrm{FI}}^{\prime \prime}$ for a normal day compared with that for the day of the eclipse including data plotted from the obervations of other investigators.

Unlabeled circles indicate Washington measurements. Points marked $\mathrm{X}$ indicate Sydney measurements. Circles marked $H$ from Henderson. Circles marked $M$ from Mimno and Wang. Circle marked K from Kenrick \& Pickard.

for disappearance of these effects was not present during the eclipse. As a result, the physical aspects of the $F_{1}$-layer appear to be about the same as during the early afternoon but with lower ionizations.

\section{OBSERVATIONS OF THE $F_{2}$-LAYER}

Figure 12 shows the $\mathrm{F}_{2}$ critical frequency $\left(f_{\mathrm{F} 2}\right)$ plotted with known limits for a number of days preceding and following the eclipse. Figure 13 shows the same data for the day of the eclipse, while figure 14 shows the comparison of the eclipse and "normal" data. It should be noted that because we are not certain whether this critical frequency is for the ordinary or extraordinary ray, no distinction in notations is made. 
It will be seen that $f_{\mathrm{F} 2}$ during the eclipse period cannot be said definitely to have undergone any marked change. A decrease of $f_{\mathrm{F} 2}$ took place during the last phase of the eclipse, but decreases of the same order are found to occur on "normal" days, notably September 1 , during about the same time. The values of $f_{\mathrm{F} 2}$ for August 27 and August 30 are, respectively, just below and just above the values of $f_{\mathrm{F} 2}$ for the eclipse day during this time. It must be recognized that these latter 2 days were magnetically disturbed, and though no direct correlation has been established between changes at $f_{\mathrm{F} 2}$ and such

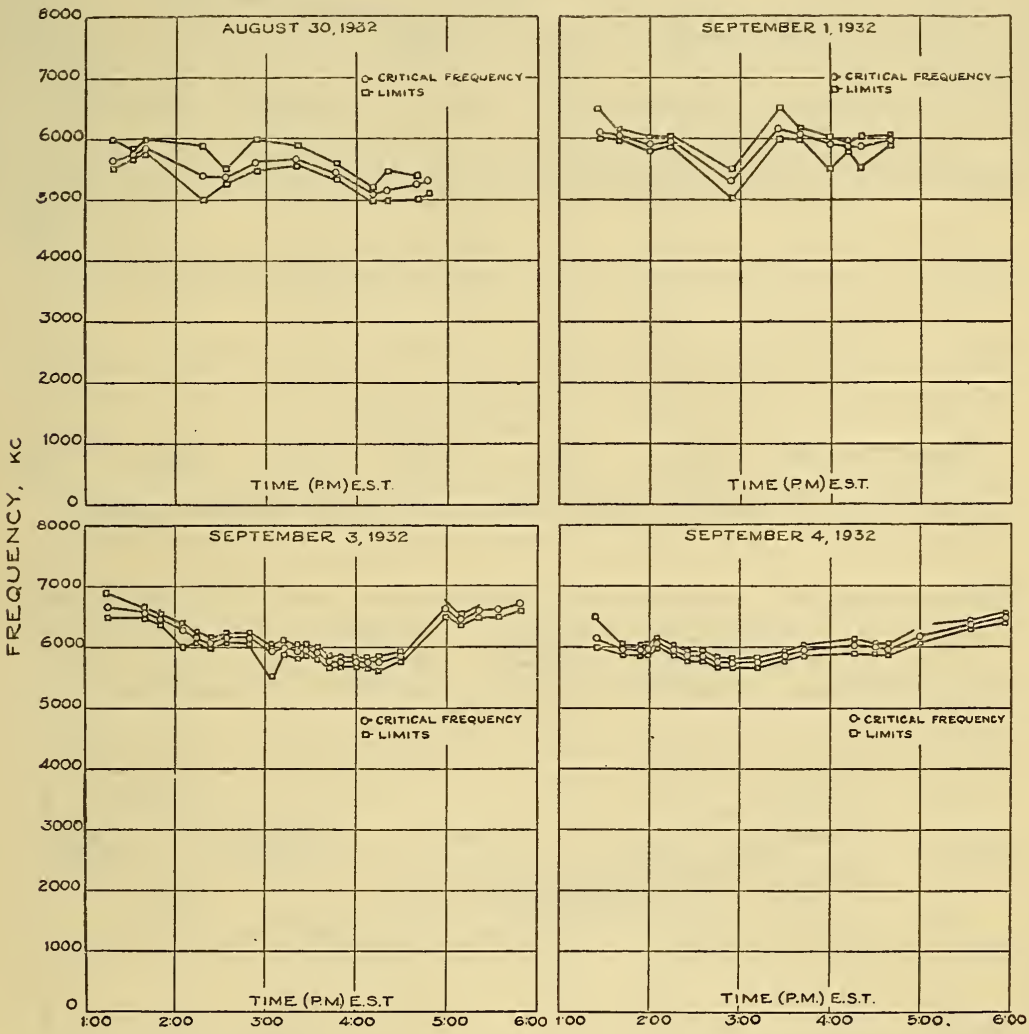

FIGURE 12.- $F_{2}$ critical frequency with limits for a number of days preceding and following the eclipse.

disturbances, it is possible that they may effect the results during these periods.

It appears, therefore, that no positive results on this can be stated. It can be said, generally, that any changes in $f_{\mathrm{F} 2}$ which might have been due to the eclipse were not large in magnitude, and were very small compared with the very large changes in $f_{\mathrm{F} 1}$ and $f_{\mathrm{z}}^{\prime \prime}$.

It has been shown by Kirby, Berkner, and Stuart ${ }^{31}$ that $f_{\mathrm{F} 2}$ does not follow the normal characteristics of the lower layers. The possibility that this critical frequency does not indicate a maximum ionization has been discussed, and it has been suggested that the 


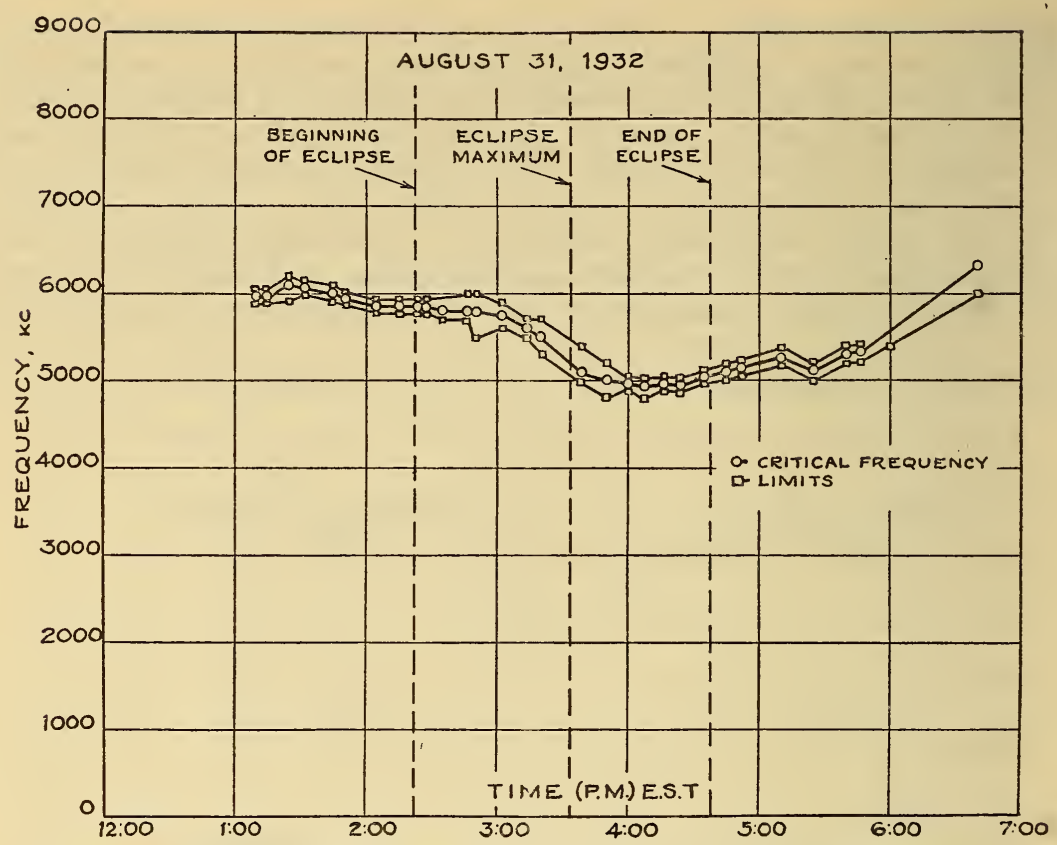

FIGURE 13.- $F_{2}$ critical frequency with limits for the day of the eclipse.

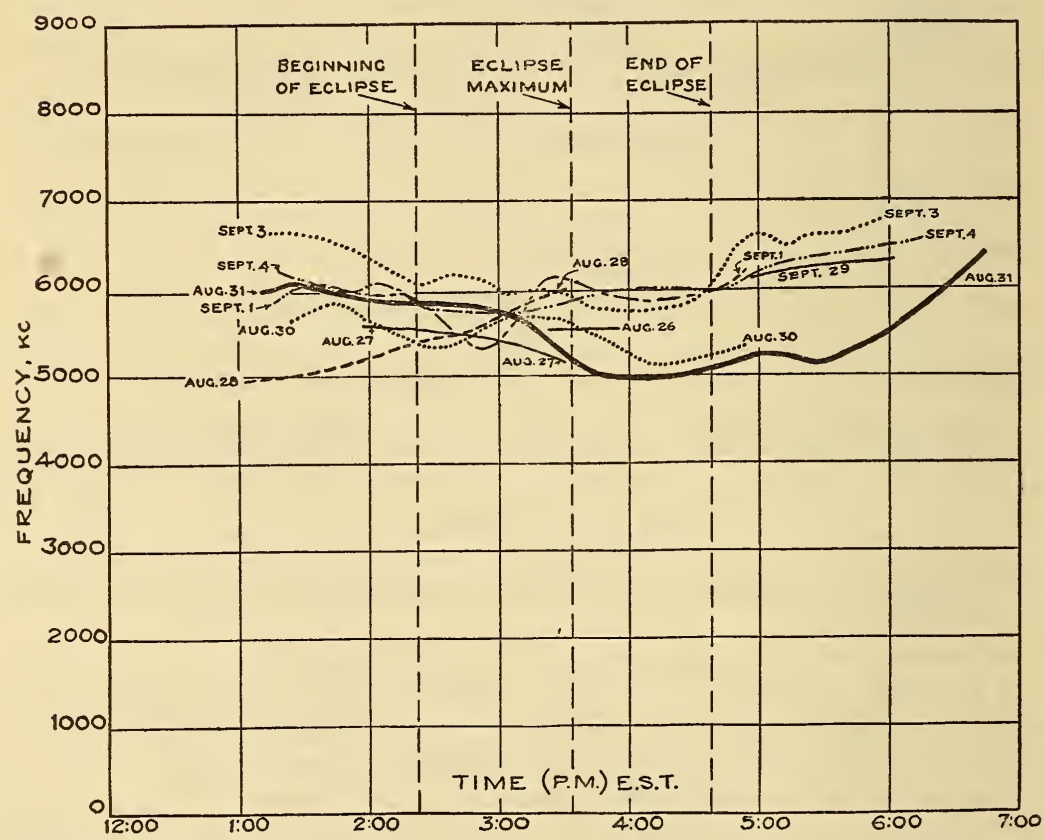

FIGURE 14.- $F_{2}$ critical frequency for the day of the eclipse superimposed on the curves of previous and succeeding days. 
determining factor is absorption rather than ionization. It appears that the observed facts can be explained on this basis. It is possible that recombination occurred in the $\mathrm{F}_{2}$-layer in the same manner as in the lower layers, but that such changes did not directly affect $f_{\mathrm{F} 2}$. From this point of view, the results obtained appear reasonable.

\section{ACKNOWLEDGMENTS}

Operations at Sydney were made possible by courtesy of the Canadian Government. The arrangements were made through the United States State Department. We wish to acknowledge the assistance given by B. Haas, Carnegie Institution of Washington; P. N. Arnold, Harvard University, and a number of our associates in the Bureau of Standards during these measurements, and to acknowledge the loan of a receiving equipment by the Carnegie Institution during this period, all of which materially aided in obtaining the observations.

Washington, August 26, 1933. 